\title{
Combined Use of TruFill DCS Detachable Coil System and Guglielmi Detachable Coil for Embolization of Meningioma Fed by Branches of the Cavernous Internal Carotid Artery
} -Technical Case Report-

\author{
Noboru KUSAKA, Takashi TAMIYA*, Kenji SugIU**, Koji TOKUnAGA**, \\ Mitsuhisa NishiguCHI, Kazuhiro TAKAYAMA, Yasuhiko MAEDA, \\ Kotaro OGIHARA, Minoru NAKAGAWA, \\ and Tsukasa NISHIURA
}

\begin{abstract}
Department of Neurosurgery, National Hospital Organization Iwakuni Clinical Center, Iwakuni, Yamaguchi; *Department of Neurological Surgery, Kagawa University, Kagawa; **Department of Neurological Surgery, Okayama University Graduate School of Medicine, Dentistry and Pharmaceutical Sciences, Okayama
\end{abstract}

\begin{abstract}
A 57-year-old female presented with a left petroclival meningioma fed by the meningohypophyseal trunk of the internal carotid artery (ICA). The enlarged tentorial marginal artery and inferior hypophyseal artery were successfully embolized with the TruFill DCS Detachable Coil System through a 0.019-inch inner diameter microcatheter. Superselective catheterization into the dorsal meningeal artery could not be achieved with the same microcatheter, because the catheter tip was too large to pass into the vessel. Subsequently the feeding artery was successfully embolized with a Guglielmi detachable coil (GDC) through a 0.016-inch inner diameter microcatheter. The patient underwent surgery without blood loss on the day after embolization. Our subjective impression was that the TruFill DCS was softer and had less resistance during insertion, whereas the GDC could be delivered through a smaller caliber system for smaller vessels. Appropriate use of the TruFill DCS and GDCs can allow efficient embolization of the feeding branches of the ICA.
\end{abstract}

Key words: meningioma, internal carotid artery, meningohypophyseal trunk, TruFill DCS, Guglielmi detachable coil

\section{Introduction}

Preoperative embolization for meningiomas of the skull base can reduce surgical blood loss, shorten operating time, reduce the risk of damage to surrounding structures, and increase the chance of complete tumor resection. ${ }^{2,4)}$ However, the vascular supply is often difficult to control because direct meningeal feeders may arise from segments of the internal carotid artery (ICA), such as the meningohypophyseal trunk and the inferolateral trunk. ${ }^{1)}$ In general, the meningohypophyseal trunk projects posteriorly and laterally from its origin in the $\mathrm{C}_{5}$

Received April 3, 2006; Accepted September 4, 2006 segment (posterior genu) of the cavernous ICA, and quickly trifurcates into three branches: the tentorial marginal artery (of Bernasconi and Cassinari), the dorsal meningeal artery, and the inferior hypophyseal artery. ${ }^{5)}$ The origin and tortuosity of these vessels may prevent successful superselective catheterization. However, if the individual branches become enlarged to supply the tumor, current endovascular techniques allow effective and safe embolization of these small vessels. ${ }^{2,5)}$ However, even if catheterization is successful, the microcatheter may not be stable enough to allow safe delivery of liquid or particle agents without the theoretical risk of intracranial reflux into the ICA.

We describe a case of petroclival meningioma treated with successful preoperative embolization of 


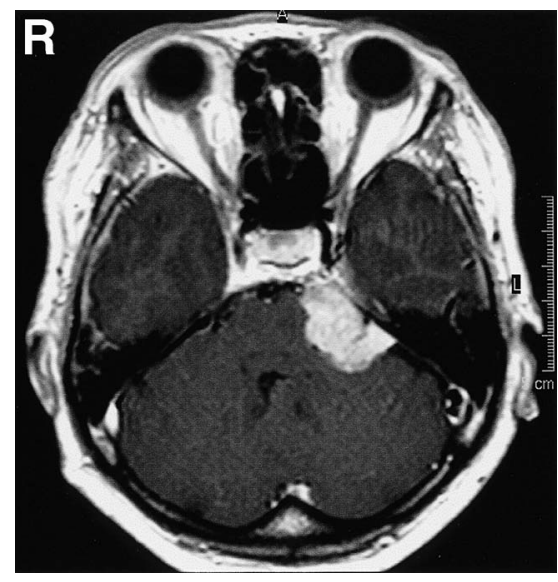

Fig. 1 Preoperative $T_{1}$-weighted magnetic resonance image with contrast enhancement demonstrating a left petroclival meningioma with compression of the brain stem.
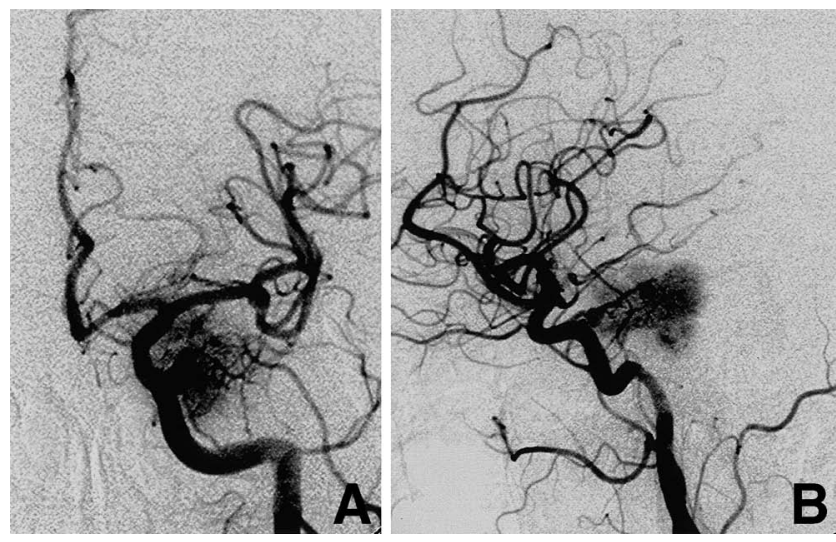

Fig. 2 Preembolization left common carotid angiograms, anteroposterior view (A) and lateral view (B), showing the enlarged meningohypophyseal trunk contributes to the supply of the tumor.


the feeding branches with combined use of the TruFill DCS Detachable Coil System (Cordis Neurovascular, Miami, Fla., U.S.A.) and Guglielmi detachable coils (GDCs) (Boston Scientific, Fremont, Calif., U.S.A.).

\section{Case Report}

A 57-year-old female presented with clinical evidence of a left petroclival meningioma, which was identified based on magnetic resonance imaging (Fig. 1). Cerebral angiography showed a tumor stain and a hypertrophic left meningohypophyseal trunk supplying most of the tumor, with the remainder supplied by a branch of the left middle meningeal artery (MMA) (Fig. 2). The tentorial marginal artery, inferior hypophyseal artery, and dorsal meningeal artery had become enlarged to supply the tumor.

After catheterization of the cervical ICA with a $6 \mathrm{~F}$ guiding catheter via the transfemoral route, superselective catheterization was performed initially for the enlarged tentorial marginal artery using a 0.019-inch microcatheter (Excelsior ${ }^{\mathbb{R}} 1018^{\circledR}$ MicroC).
Fig. 3 A: Left internal carotid angiogram after embolization of the tentorial marginal artery from the meningohypophyseal trunk with two TruFill DCS coils (arrowhead). B: Selective inferior hypophyseal angiogram after catheterization with a 0.019-inch inner diameter microcatheter. C: Left internal carotid angiogram after embolization of the inferior hypophyseal artery. Four TruFill DCS coils (arrows) detached into the inferior hypophyseal artery are visible.

catheter: 2.0F outer diameter [OD], 0.019-inch inner diameter [ID]; Boston Scientific) and Transend ${ }^{\mathrm{TM}}$ EX .014 Floppy Guidewire (0.014-inch; Boston Scientific). The microcatheter was easily inserted into the distal tentorial marginal artery. Two TruFill DCS coils (helical coil; $2 \mathrm{~mm} / 2 \mathrm{~cm}$ ) were delivered easily without resistance during insertion and detached, resulting in complete elimination of the blood supply to the tumor (Fig. 3A). In a similar fashion, the enlarged inferior hypophyseal artery was easily occluded using four TruFill DCS coils (helical coil; one $2 \mathrm{~mm} / 2 \mathrm{~cm}$ coil, three $2 \mathrm{~mm} / 3 \mathrm{~cm}$ coils) without resistance during insertion (Fig. 3B,

However, superselective catheterization of the dorsal meningeal artery could not be achieved with the same microcatheter, because the catheter tip was 


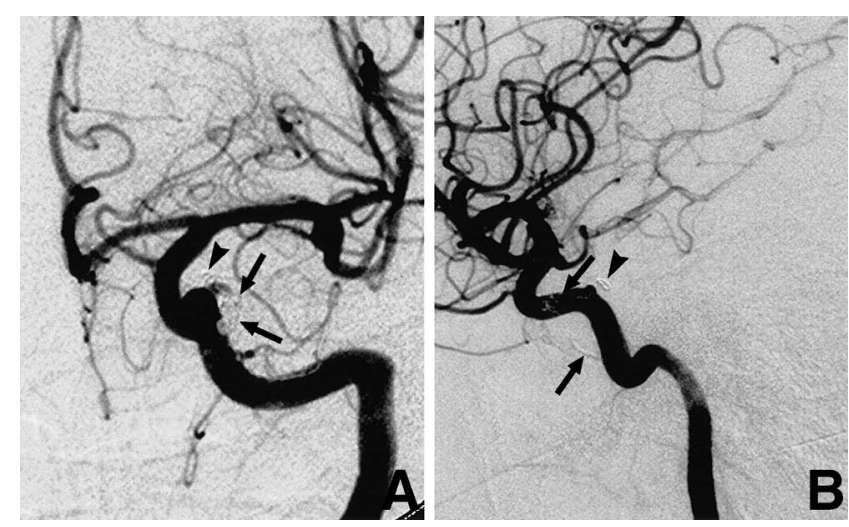

Fig. 4 Left internal carotid angiograms after embolization, anteroposterior view (A) and lateral view (B), showing complete devascularization of the tumor. TruFill DCS coils (arrows) were detached into the tentorial marginal artery and inferior hypophyseal artery, and a Guglielmi detachable coil (arrowhead) was detached into the dorsal meningeal artery.

too large to insert into the vessel. Subsequently, the artery was selectively catheterized with unstable position using a 0.016-inch microcatheter (Excelsior ${ }^{\circledR}$ SL-10 Microcatheter: 1.7F OD, 0.016-inch ID; Boston Scientific) and the Transend ${ }^{\mathrm{TM}} .010$ Guidewire (0.010-inch; Boston Scientific). A single GDC (GDC UltraSoft Coil: $2.0 \mathrm{~mm} \times 1 \mathrm{~cm}$; Boston Scientific) was successfully detached in the proximal portion of the dorsal meningeal artery (Fig. 4). However, this coil was introduced with some difficulty due to the microcatheter instability, including kick back several times, and some resistance during insertion. Finally, the posterior MMA supplying the tumor was occluded using 250-500 $\mu \mathrm{m}$ polyvinyl alcohol particles.

Postembolization angiography demonstrated complete elimination of the supply to the tumor. No immediate or delayed complications occurred. The patient underwent successful surgery without blood loss using the anterior transpetrosal approach on the day after embolization.

\section{Discussion}

The TruFill DCS Detachable Coil System was recently introduced in Japan, and consists of a shaped 0.012-inch platinum coil attached to a delivery wire-1ike tube, and is detached through a hydraulic detachment mechanism. ${ }^{6)}$ The TruFill DCS is usually used to embolize cerebral aneurysms, which can be positioned and repositioned at will, then detached in a safe and controlled fashion with reduced risk of unwanted embolization of normal intracranial vessels.

The cavernous and petrous ICA feeding vessels were successfully occluded using a new crescentshaped GDC, but this device is not available. ${ }^{2)} \mathrm{We}$ have also used regular GDC in three cases (including this one) for preoperative embolization of petroclival meningioma fed by the cavernous ICA feeding branches (unpublished data in one case). ${ }^{3)}$ Our clinical experience gave us the subjective impression that the TruFill DCS is softer and has less resistance during insertion than the GDC, and seems not to cause trauma for vessels. However, a larger microcatheter system profile is necessary for the TruFill DCS, whereas the GDC can be delivered through a smaller caliber system (0.010-inch ID microcatheter), so is particularly useful for smaller vessels. Appropriate use of the TruFill DCS and the GDC can achieve more efficient embolization for the feeding branches of the ICA.

The present case shows that the TruFill DCS can be used to successfully embolize small feeding vessels such as the branches of the cavernous ICA effectively in a controllable manner.

\section{References}

1) Connors JJ III, Wojak JC: Embolization: meningioma, in: Interventional Neuroradiology. Philadelphia, WB Saunders, 1999, pp 100-120

2) Guglielmi G: Use of the GDC crescent for embolization of tumors fed by cavernous and petrous branches of the internal carotid artery. J Neurosurg 89: 857-860, 1998

3) Katsumata A, Kusaka N, Sugiu K, Nakashima H, Date I, Ohmoto T: [Use of the GDC for embolization of a tumor fed by a cavernous branch of the internal carotid artery]. No Shinkei Geka 29: 565-569, 2001 (Jpn, with Eng abstract)

4) Latchaw RE: Preoperative intracranial meningioma embolization: technical consideration affecting the risk-to-benefit ratio. AJNR Am J Neuroradiol 14: 583-586, 1993 (comment)

5) Robinson DH, Song JK, Eskridge JM: Embolization of meningohypophyseal and inferolateral branches of the cavernous internal carotid artery. AJNR Am J Neuroradiol 20: 1061-1067, 1999

6) Slob MJ, van Rooij WJ, Sluzewski M: Coil thickness and packing of cerebral aneurysms: a comparative study of two types of coils. AJNR Am J Neuroradiol 26: 901-903, 2005

Address reprint requests to: Noboru Kusaka, M.D., Department of Neurosurgery, National Hospital Organization Iwakuni Clinical Center, 2-5-1 Kuroiso-cho, Iwakuni, Yamaguchi 740-0041, Japan. e-mail:kusaka@iwakuni-nh.go.jp 